\title{
P-0880: NON-INSULIN MEDICATION ADHERENCE IN DIABETES: DATA FROM A BRAZILIAN NATIONAL SURVEY, PNAUM
}

M.M. Milward de Azevedo Meiners ${ }^{1}$, N. Urruth Leão Tavares ${ }^{1}$, S. Serrate Mengue ${ }^{2}$,

\author{
L. S. P. Guimarães ${ }^{3}$, E. Merchán-Hamann ${ }^{1}$
}

${ }^{1}$ Post Graduate Program on Public Health, Health Sciences Department, University of Brasilia, Brazil 2Post Graduate Program on Epidemiology, University of Rio Grande do Sul, Porto Alegre, Brazil; ${ }^{3}$ Hospital of Clinics of Porto Alegre, University of Rio Grande do Sul, Brazil

\section{michelinemeiners@gmail.com}

\section{Introduction:}

Brazil has set up health policies for prevention and care of people with diabetes in order to ensure, mainly, access to medicines (1). In recent years the access to medicines was improved in Brazil, especially for chronic conditions. Nowadays it has been estimated $95 \%$ of access for this population. Almost eight percent of antihyperglycemic agents are available totally for free, funded by the Government (2). However, improvements in adherence among persons with diabetes are needed to achieve better results on healthcare management. Adherence to prescribed medications is the key factor of healthcare quality (3-4).

Aims:

Our objective is to evaluate self-reported medication adherence from a large population-based study among people with diabetes in Brazil.

\section{Methods:}

The National Survey on Access, Use and Promotion of the Rational Use of Medicines in Brazil, with acronym PNAUM, was realized between 2013 and 2014. The prevalence rates from the survey were weighted to ensure national and regional representation (5). Considering all participants of the survey, we selected those who self-reported diabetes. The prevalence of diabetes was $6.8 \%$ among participants with $\geq 20$ years old. Poor adherence was evaluated among those factors appointed by World Health Organization to contribute with non-adherence and that were available in the PNAUM database: socio-demographic factors, system and health team related, disease, patient related and treatment related (6). An univariate regression was applied to identify the factors associated with medication adherence.

\section{Results:}

A 73,6\% percent of participants reported good or probably good medication adherence and $26,4 \%$ poor or probably poor adherence (Figure 1 ). The factors significantly associated with poor adherence in univariate analysis were disease, treatment or healthcare-related: limitations from disease $(p=0,001)$, poor selfhealth perception $(p=0,008)$, taking $\geq 3$ medicines $(p=0,016)$ and follow-up by $>1$ physician $(p=0,011)$ (Table 1$)$.

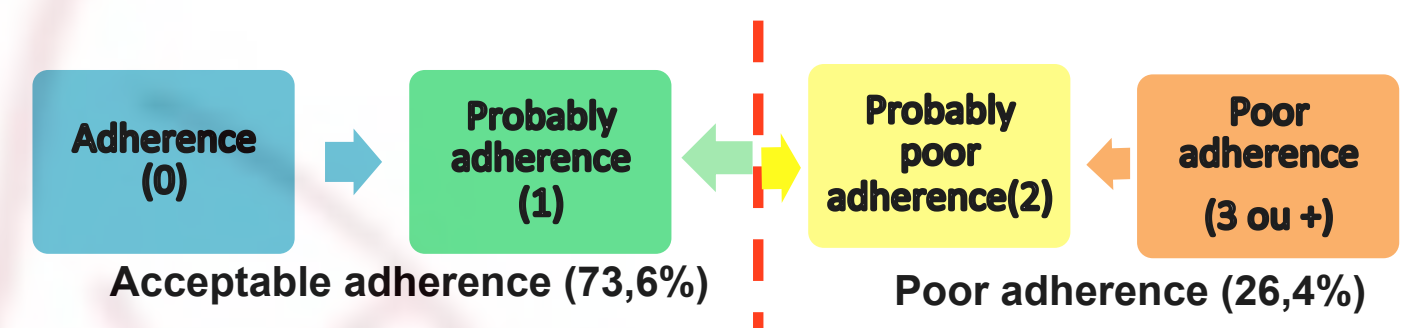

Figure 1 - Representation of the variable adherence to treatment according to the Brief Medication Questionnaire score, which analyzes the use of non-insulin-antihyperglycemic agents. PNAUM, Brazil, 2014.

Table 1 - Unadjusted Prevalence Ratio (UPR) of poor adherence, using the Poisson hierarchical model in adults ( $\geq 20$ years) with diabetes using non-insulin- antihyperglicemic agents ( $n=1689)$. PNAUM, Brazil, 2014.

\begin{tabular}{|c|c|c|c|}
\hline & & \multicolumn{2}{|c|}{ Univariate Regression } \\
\hline \multicolumn{2}{|c|}{ Variables } & UPR [IC95\%] & $\mathbf{p}$ \\
\hline \multicolumn{4}{|l|}{ System and health team } \\
\hline \multirow[t]{2}{*}{ Number of doctors } & 1 & 1 & \\
\hline & $>1$ & $1,34[1,07 ; 1,67]$ & 0,010 \\
\hline \multicolumn{4}{|l|}{ Disease } \\
\hline \multirow[t]{3}{*}{ Limitation } & None & 1 & \\
\hline & A little & $1,39[1,08 ; 1,79]$ & 0,010 \\
\hline & Limits & $1,62[1,25 ; 2,10]$ & $<0,001$ \\
\hline \multicolumn{4}{|l|}{ Patient } \\
\hline \multirow[t]{3}{*}{ Health perception } & Very Good / Good & 1 & \\
\hline & Regular & $1,21[0,98 ; 1,49]$ & 0,081 \\
\hline & Bad / Very Bad & $1,62[1,20 ; 2,18]$ & 0,002 \\
\hline \multicolumn{4}{|l|}{ Treatment } \\
\hline \multirow[t]{3}{*}{ Number of medicines in use } & 1 to 2 & 1 & \\
\hline & 3 to 4 & $1,30[0,82 ; 2,07]$ & 0,269 \\
\hline & 5 or more & $1,66[1,06 ; 2,62]$ & 0,027 \\
\hline
\end{tabular}

\section{Discussion:}

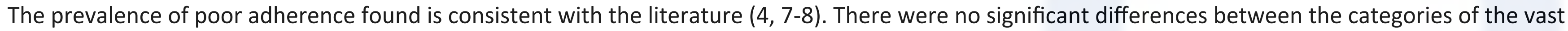
majority of variables. However, the role of a physician in the coordination of healthcare seems to influence better adherence (9).

The homogeneous prevalence of low adherence did not allow establishing statistical significance to many factors associated with it in the literature.

\section{Conclusion:}

It is needed medication adherence in a country with a high level of access to antihyperglycemic agents to reach effectiveness of healthcare resources (7).

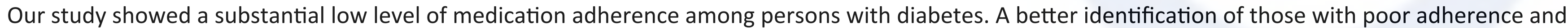
its associated modifiable risk factors can guide health professionals to develop more suitable individual therapeutic approach and improve healthcare quality (8).

\section{References:}

(1) Brazil. Federal Law 11.347 (27th. September 2006), Act for the free distribution of drugs and necessary materials for its application and capillary glycaemia monitoring for persons with diabetes mellitus enrolled in diabetic education programs. Diário Oficial da União, Brasília, DF, 28 de set. 2006. Seção 1, p. 1.

(2) Urruth Leão Tavares, Noemia, et al. "Acesso gratuito a medicamentos para tratamento de doenças crônicas no Brasil." Revista de Saúde Pública 50.2 (2016). DOI: 10.1590/S1518-8787.2016050006118

(3) Sokol, Michael C., et al. "Impact of medication adherence on hospitalization risk and healthcare cost." Medical care 43.6 (2005): $521-530$.

(4) Krass, Ines, P. Schieback, and T. Dhippayom. "Adherence to diabetes medication: a systematic review." Diabetic Medicine 32.6 (2015): 725-737. DOI: 10.1111/dme.12651

(5) Serrate Mengue, Sotero, et al. "Pesquisa Nacional sobre Acesso, Utilização e Promoção do Uso Racional de Medicamentos (PNAUM): métodos do inquérito domiciliar." Revista de Saúde Pública 50.2 (2016). DOI: 10.1590/S1518-8787.2016050006156

(6) World Health Organization. Adherence to long-term therapies: evidence for action. Geneva: WHO; 2003.

(7) Tiv, Michel, et al. "Medication adherence in type 2 diabetes: the ENTRED study 2007, a French population-based study." PLoS One 7.3 (2012): e32412. DOI: 10.1371/journal.pone.0032412 (8) Curkendall, Suellen M., et al. "Predictors of medication adherence in patients with type 2 diabetes mellitus." Current medical research and opinion 29.10 (2013): $1275-1286$. DOI: 10.1185/03007995.2013.821056 